\title{
Las tres etcéteras del Libertador
}

\author{
por \\ Mario Briceño Perozo
}

Don Ricardo Palma da el título de esta página a una de sus ingeniosas y picarescas tradiciones peruanas en que, con su estilo ameno, persuasivo, sonoro, subyugante, destaca un episodio cuyo personaje central es Simón Bolívar.

En las crónicas de Palma se enlazan magistralmente la historia, la leyenda y la facundia imaginativa del autor, pero cruzado todo de tal forma que la gran masa de lectores difícilmente acierta en la separación de una cosa de la otra, hasta el punto de aceptar los datos y pormenores allí consignados como el reflejo de un testimonio indiscutible.

Es lógico aceptar que un hombre de la talla de Bolívar se tornara, aún sin él sospecharlo, siquiera, en protagonista de hechos vinculados lal prestigio, al poder, alas virtudes y a los defectos de su persona, pero, sin duda alguna, que de acuerdo con la mentalidad y simpatía del narrador, los referidos hechos se configuran o deforman para bien o para mal de aquel a quien se le atribuyen.

En el presente caso, Bolívar es inspirador del relato por ser árbitro del poderío político en aquellas regiones y por su tama de mujeriego. La escena la fija Palma en 1824, y la sitúa en la Villla de San Ildefonso de Caraz, cuyo Gobernador Don Pab̆lo Guzmán, recibe, a fines de mayo, un oficio del Jefe del Estado Mayor del ejército republicano, en que le anuncia que dentro de poco llegará a la localidad el Libertador, por lo que le previene alistar cómodo y decente alojamiento, con buena mesa, buena cama, etc., etc., etc.

Más, como el señor Guzmán ignora el significado de las etcéteras, resuelve convocar a los notables del pueblo para que le despejen la incógnita. Uno de los convocados, haciendo gala de sus conocimientos de latín, opina que etcétera quiere decir 
y lo demás; y luego de las intervenciones de los otros, acordes con la del primer expositor, se concluye que colocadas las etcéteras después del encargo de buena cama, y sabedores como son de la inclinación hacia Venus del Libertador, aquello no significa otra cosa que reservarle al ilustre visitante una dama por etcétera. Por lo que se apremia al Gobernador a que proceda, sin demora, a localizar tres muchachas en el vecindario para cumplir la importante misión.

Don Pablo encomendó la consecución de las ninfas al Capitán Martín Gamero, quien dos horas antes del arribo de Bolívar a Caraz, ya tenía reclutadas las mozas de las etcéteras, las que, para mayor seguridad fueron encerradas, de orden superior, en calidad de presas, en el inmueble destinado para alojamiento del Libertador. Este llegó a las dos de la tarde y de inmediato se empapó del asunto, por lo que ordenó la libertad de las jóvenes cautivas, y después de amonestar severamente a Don Pablo Guzmán, lo sacó en volandas de su Gobernación.

Palma comenta que la desgana de Bolívar en esta oportunidad, se debía a que, desde Huaylas, traía por compañera a una doncella de 18 primaveras, Manolita Madroño, la más guapa criatura de aquellos pagos. (1).

Años después, cuando al pintoresco ex-Gobernador Don Pablo Guzmán, preguntaban algunos curiosos —entre estos segu-

(1).-No acicrta el macstro peruano con este comentario, puesto que Bolívar con la Madroño o sin clla, no cra caballero dado a la recluta de mujeres, ế sabía ganarse cl corazón femenino de otra manera. de suerte que esa actitud frente a la ocurrencia del bueno de Guzmán, se ajusta al más lógico y propio de sus procederes.

También desacertó Palma al consignar en esa misma crónica que el Libertador habla gastado, con cargo al erario del Perú, la suma de 8.000 pesos en agua de colonia, cunnuw. como lo demostró el historiador Correa, en cl Diario de gastos de Bolívar en el palacio de la Magdalena -2 de diciembre de 1824 a 8 de abril de 1825- sólo aparece una partida por aquel concepto, que monta a cuatro pesos y cuatro reales.

Bolfvar -escribe Correa- no era el pródlgo, no era el botarate que plntaban sus enemigos; el hombre que lba a convecar el congreso de Panamá v a fljar los destinos políticos de América, remendaba sus botas, usnba medlas de algodón y gastaba en su mesa un vino de Burdeos cuyo preclo no excedía de catorce pesos la caja.

Luis Correa. El Llbertador en el Perú. Boletín de la Academia Nacional de la Historia. Calacas, abril-junio de 1928. No 42. Tomo XI. Pág. 142.

Lceuña señala que lo traído por Palma sobre gastos en agua florida, no es original, pucs antes lo habia dicho Pruvonena, al insinuar la existencia de una partida de ocho inil pesos que se dice fueron invertidos en Agua de Colonia, comprada para Bolivar.

Lecuna llama a Pruvonena "famoso calumniador $c$ inepto y villano polftico" y coloca después de su nombre, entre paréntesis. el de Riva Agüero.

Vid: Vicente Lccuna. Catálogos de Errores y Calumnlas en la Historla de Bolívar. The Colonial Press Inc. New York, 1958. Tomo III. Pág. 34.

Es correcta la cita de Lecuna, lo transcrito puede lecrse en P. Pruvonena: Memorlas y Documentos para la Hilstorla de la Independencla del Perú. Librería de Garnier Hermanos, París, 1858. Tomo I. Pág. 196.

La falsedad del memorialista surge a las claras en su dubitación: que se dice, cuando cualquiera cree que está hablando frente a documentos en que consta la partida gastada. 
ramente, Don Ricardo Palma (2) - acerca de aquella lamentable equivocación, él se justificaba de esta guisa: La culpa no fue mia, sino de quien en el oficio no se expresó con la claridad que Dios manda. (3).

Palma, como se sabe a lo largo de Hispanoamérica, fue poeta, escritor, político, periodista, crítico, lingüista, polemista e historiador, pero nada le ha dado tanta nombradía como su obra de tradicionista, labrada en prosa limpia y armoniosa, con tonalidades románticas y plena de reminiscencias arrancadas a la Colonia y a la Independencia.

Si antes, a partir de 1863, sus tradiciones eran conocidas solamente en el Sur, en 1872, agrupadas en libro, recorrcrán todo el Continente y saltarán sus fronteras, y serán tema de inspiración para otros maestros del idioma.

Esto último lo decimos porque Las tres etcéteras del Libertador, son la columna vertebral de una obra dramática de Don José María Pemán y Pemartín, intitulada Los tres etcéteteras de Don Simón, dada a conocer en España, a los treinta y nueve años del fallecimiento de Palma (4).

El autor la llama regocijada farsa, original suya, dividida en dos partes, y la segunda en dos cuadros. Se desarrolla en el pueblo "La Fernandina" hacia Sierra Morena, cerca de Jaén, en el ámbito histórico de 1810, época del Rey José Bonaparte.

Don Lucas Tinajero, Alcalde de "La Fernandina", recibe de la superioridad un oficio en que se le comunica la próxima iilegada al pueblo de su mando, dePGobernador General de la Provincia, Don Simón Belalcázar, quien se alojará en casa del señor alcalde, donde se le preparará buena cena, vinos escogi. dos, cama ancha y blanca, etcétera, etcétera, etcétera...

Ante la inminente visita del personaje, Don Lucas decide consuitar con los señores del Concejo, y entre las cosas que discuten está la del significado de las tres etcéteras que siguen a cama ancha y blanca, habida cuenta de la fama de Don Simón

(2).-Guzmán, según el tradicionista peruano, murió en 1882. Para entonces, tenía Palma 49 años, pues habia nacido cn Lima, el 7 de febrero de 1833 . V. Pág. 109 .

(3).-Ricardo Palma, Tradiclones Peruanas. Espasa-Calpe, S. A. Madrid, 1953. Tomo

(4).-Don Ricardo murí́ el 6 de octubre de 1919. Uno de los más autorizados voceros venezolanos. al registrar la noticia del deceso, le dedica, entre otros, los siguientes conceptos: Patriarca de las letras peruanas... Poséfa como escritor dos cunlidades maestras: la soltura y elegancia del estilo y la gracla Ingenua, un tanto apicarada, que le daban cierto parentesco Ideal con los escritores españoles del slglo de oro... Su imuerte es una pérdida Irreparable para el Perú y las demas naciones do un mlsmo origen, que pueblin el Continente Americano.

"El Universal". Caracas, jueves, 23 de octubre de 1919. No 3.747. Página 1. 
Belalcázar, por su energía, aventuras de mujeriego, y llegar después de meses de largas caminatas sierra adentro.

Uno de los circunstantes hace alusión al latín y Don Lucas aduce que consultó el Diccionario y que por eso sabe que aquello significa algo que se da por supuesto y entendido... aunque no se nombre. Por lo cual la conclusión es que al precipuo visitante se le deben guardar tres muchachas, $y$ el Alcalde ha de localizarlas en "La Fernandina".

Después de algunas peripecias, las damas son llevadas a la morada del Gobernador, quien se manifiesta muy amable cón las tres, pero sin llegar a prendarse de ninguna, antes bien las trata con tono paternal y procura solucionarles sus problemas domésticos; finalmente, Belalcázar recomienda al Intendente -que fue quien escribió el oficio para el Alcalde- prescindir de las etcéteras en la correspondencia, y a Don Lucas que aprenda un poco de latín, que etcétera quiere decir " $\mathrm{y}$ todo lo demás".

Esta comedia fue estrenada en Madrid, el viernes 7 de marzo de 1958, en el Teatro Club Recoletos, baio la dirección de Manuel Benítez Sánchez-Cortés, constituyendo un éxito rotundo (5).

Compárese las síntesis argumentales que hemos traído a estas páginas y se verá el parentesco tan cercano que existe er. tre la crónica de Palna y la pieza de Pemán. Hasta las iniciales de Don Simón Bêlalcázarcoinciden con las del Libertador.

Pemán, comorpalmaçces eun polifacético: poeta, escritor, dramaturgo, periodista, crítico, historiador. Al igual que Villaespesa y Narquina ha cultivado el drama de evocación histórica, y es el más alto orador de España.

El divino impaciente, Cuando las Cortes de Cádiz, Cisneros, La Santa Virreyna, Por la Virgen Capitana, son obras teatrales de Pemán basadas en motivos que pertenecen a la Historia.

$\mathrm{Y}$ como historiador y cronista, sobresalen sus trabajos: Historia de Tres Días (27-28-29 de marzo de 1939), La Historia

(5).-El público obligó al autor a saludar, desde el escenario, en unión de los intérpretes Ramón Elias, Pedro Beltrán, Antonio Martínez, Rosa Ma. Vega, Mary Carrillo, Alvaro Fontana, Guillermo Marin, Gracia Morales y Pablo Sanz.

EI comentario general de la prensa, fue elogioso para Pemán, a pesar de que algun crítico señaló reparos a "cicrtos chistes de tono demasiado subidos".

Vid: Francisco Alvaro. El Espectador y la Críllc.a (El Teatro en España en 1953). Editorial Sever-Cuseta. Valladolid, 1959. Págs. 35 a 38. 
de España contada con sencillez, y Crónicas de antes y después del Diluvio (6).

Como Palma, Pemán es prosador castizo que atrae y deleita, que enseña y cautiva. De seguro que el eximio escritor gaditano compuso Los tres etcéteras de Don Simón llevado por el curioso gracejo contenido en Las tres etcéteras del Libertador. (7). La Fernandina en la Sierra Morena es San Ildefonso de Caraz en la Cordillera Andina, y el atribulado alcalde Don Lucas Tinajero, encarna, indudablemente, al cándido Goberna. dor Don Pablo Guzmán.

Las costumbres y peculiaridades de los hombres y pueblos de la América csnañola se identifican con los de la Peninsula, porque fueron tallados a su imagen y semejanza, por eso encuadra perfectamente una escena peruana en el tarimón hispánico, y un tradicionista criollo influye en la obra de un maestro de la Madre Patria.

(6).-Don José Maŕa Pemán, a propuesta de los numerarios Doctores Cristóbal L. Mendoza, Héctor Parra Márquez y Angel Francisco Brice fue elegido miembro corres. pondiente de la Academia Nacional de la Historia. Esta clección tuvo lugar el 16 ce abril de 1964 y contó con el voto unánime de los académicos presentes.

(7).-A rafz del estreno de su farsa, Penlón declaró: Ya anécdota que sirve de arranque a los tres etcéteras de Don Slmón, se cuenta cn crónicas antlguas en torno a algún personaje hlstórlco. Francisco Alvaro, ob. cit. Página 35.

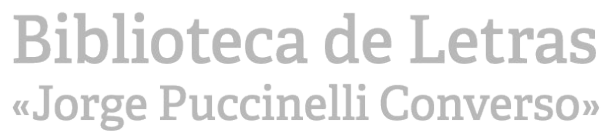

